\title{
THE QUALITY OF INTERIOR SPACE IN THE ISLAMIC STYLE
}

\author{
Dr. Oday Qusay Abdulqader \\ Architectural Eng. Dept., Engineering Col., University of Mosul (UoM), Iraq. \\ (Email: odaychalabi@gmail.com)
}

Received date: 20-02-2019

Revised date: 01-04-2019

Accepted date: 07-09-2019

Published date: 10-09-2019

To cite this document: Abdulqader, O. Q. (2019). The Quality of Interior Space in The Islamic Style. International Journal of Heritage, Art and Multimedia, 2(6), 01-07.

DOI: $10.35631 /$ ijham.26001

\begin{abstract}
The interior design of the Islamic style in traditional cites included tangible and intangible influences, which organized the interior space according to the needs of the users and following the rules of Islam as a religion and cultural values. The quality of the interior space referred to the three points, the Rules, Elements, and Factors. However, the designers face difficulties in designing an interior space within the Islamic style. The studies in the Islamic interior design show the elements and component of the style, but few of these studies analyze in depth the quality of this style, especially, heritage houses. The research question of the current study is "What are the original components, rules, and factors that reflect the quality of the interior design of the Islamic style". The aim of the study is to identify these components, rules, and factors as a guideline. The study used a mixed methodology; the qualitative mode used the in-depth interview with experts selected by purposeful sampling technique. While the quantitative mode used a checklist to observe the visual analysis of the interior space of the selected buildings. The selected building was chosen under special criteria depending on the heritage value and availability of information. The results showed that the quality of interior design reflected by the level of the details of the interior elements. However, $72 \%$ of samples reflected the originality of the design. The quality of interior space in traditional and heritage houses in old Mosul City related to the details of the interior elements, such as materials.
\end{abstract}

Keywords: Interior Space, Old Mosul City, Heritage Houses, Islamic Style

\section{Introduction}

The interior space of the Islamic style has special characteristics, which reflect the spirit of Islamic style in the interior space. However, the origin interior space of the Islamic style is consider the guideline to create an interior space with original settings. The quality of the space in the present study in represented in the settings of the interior space, which including the rules, elements, and factors of the interior space. The interior architecture elements can affect the quality of the space through the physical components (Mahmoud, 2017). The quality of 
interior space is connected to the quality of the elements, which is used to achieve the cultural and traditions needs. Each culture have a special setting of these elements influences by the culture value (Zanten, 2002). Religion is one of the modifier of the interior design elements, which can impacts the prototype of the space. The relation between the culture need and interior design represented in the collecting of the elements in the space (Weinthal, 2013; Ujang, 2012). Hedayat (2012) highlighted that architecture, interior design, and fashion are firstly facing the culture and religion needs, which is normally adapted from the users to be ready to use in the interior space. The current study focus in the building that used by Muslims as a case study to find the main themes of influences in the interior design. From this point, the elements of the interior design of the Islamic style is the focusing of the current paper to find out the original components, rules, and factors that reflect the quality of the interior design of this style.

Few literatures deal with Islamic interior design. Moreover, the original Islamic style going to disappear because of the excessive modification, which shifted the originality of the style and affect the spirit of the style. This shifting is the main problem of the current study. The research question of the current study is "What are the original components, rules, and factors that reflect the quality of the interior design of the Islamic style". Therefore, the aim of the study is to identify these components, rules, and factors as a guideline. By finding the minimum elements, rules and factors that can used by the designers in the contemporary era to create an interior space with Islamic style. The objective of the study is "to determine the minimum settings of the Islamic interior design elements, rules, and factors". The previous studies used to generate the framework of the study, which included studies about Islamic style, interior elements, and principles of design.

\section{Literature Review}

Islamic style is influenced by religious and cultural values, which is presented in various types of buildings such as, Masjid, Madrassa (school), market, and house. Islamic style started during and after the lifetime of Prophet Muhammad (Salah Allah Alih Wasallam), which represent the original type of the style. It is started from the first Masjid in Madinah (Masjid Al-Nabawi) when Muslims needed an interior space to perform the Salah. Therefore, the building in that time was simple and included few elements (Fletcher, 2008). Islamic style may be identified with the following design elements, which were inherited from generations. These elements are; Minarets or towers, derivation of the word, a four-Iwan plan, Mihrab, Domes, Iwans, Geometric patterns, courtyard, small and high position openings. Moreover, the Islamic style have special characteristics, such as, privacy setting, simplicity, clearness, schilling, and functionality (Burckhardt, 2009; Fletcher, 2008; Hillenbrand, 1999).

The interior design in the Islamic buildings included elegant elements, which is mostly included text and geometric pattern with special colours. These patterns are a decorative element that used in various buildings type. However, some elements are functional elements such as, the handrail, arches, columns, iron work, and tiles (Figure 1 and 2). Each building included cultural effects in addition to the religion affects. The courtyard house consist the essential element, but each culture added the identity of the place of that culture. Jasim (2015) mentioned that courtyard is a heart pulsed of Islamic architecture. Its sources is of ancient civilization of Mesopotamia. Courtyard is one of the Sumerian architecture figuration. In Islamic architecture courtyard is of multi functions (Al-Jameel \& Haj Kasim, 2012). 

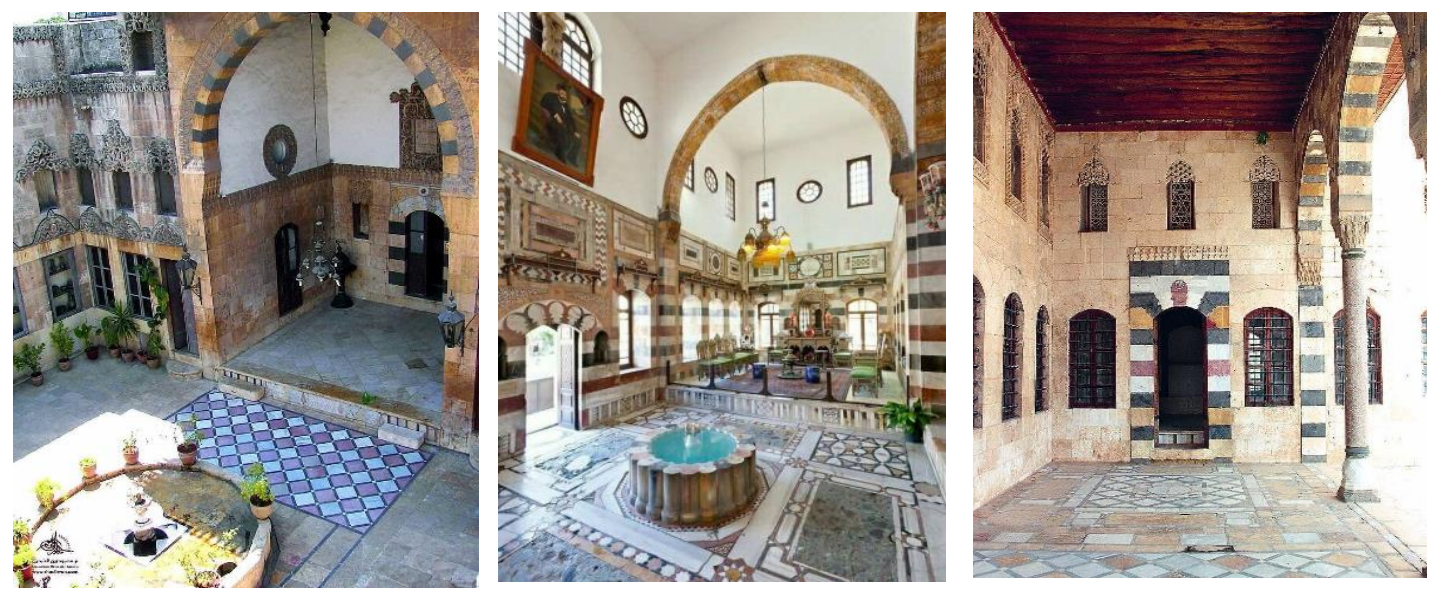

Figure 1: Samples of Interior Space of Syrian Houses. Source: (Alabidin, 2016)
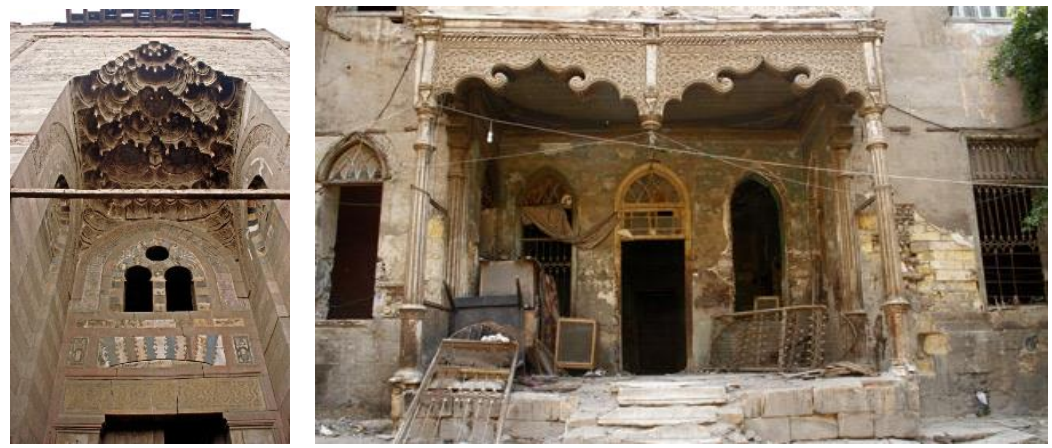

Figure 2: Sample of Decorative Elements in The Courtyard

Source: (Al-Darb Al-Ahmar District Mosques, 2017)

The principles of the interior design, that mostly used in the creating of the space, were mentioned by researchers in general (Caan, 2011). The Islamic style deal with the principles of design in-depth with spiritual vision. However, the proportion principles widely used in the design of the Islamic buildings, which reflect the quality of the style as Kamel and Elhalaby (2011) and Thanoon (2007) highlighted. There are two level of used, relationship between elements and principles of the elements itself. The symmetry, balance, rhythm, scaling, and proportion are easily to realize in the interior space of the Islamic buildings. Moreover, variety vs unity used in the overall level (AMRO, 2014; Abdulrahman \& Alimam, 2009). Foroozani (1991) mentioned the following principles; Scale, Harmony, similarity, symmetry, contrast, variety, unity, order, and repetition.

\section{Framework of The Study}

The framework of the current study generated according to the aim of the study. Moreover, the previous studies contributed to the framework, which in total divided the quality of interior design of the original interior elements in the Islamic interior style to three main point, components, rules, and factors. These three aspects are the main points that influences the space to be used by daily Muslims users. Figure 3 show the relations between the aspects. 


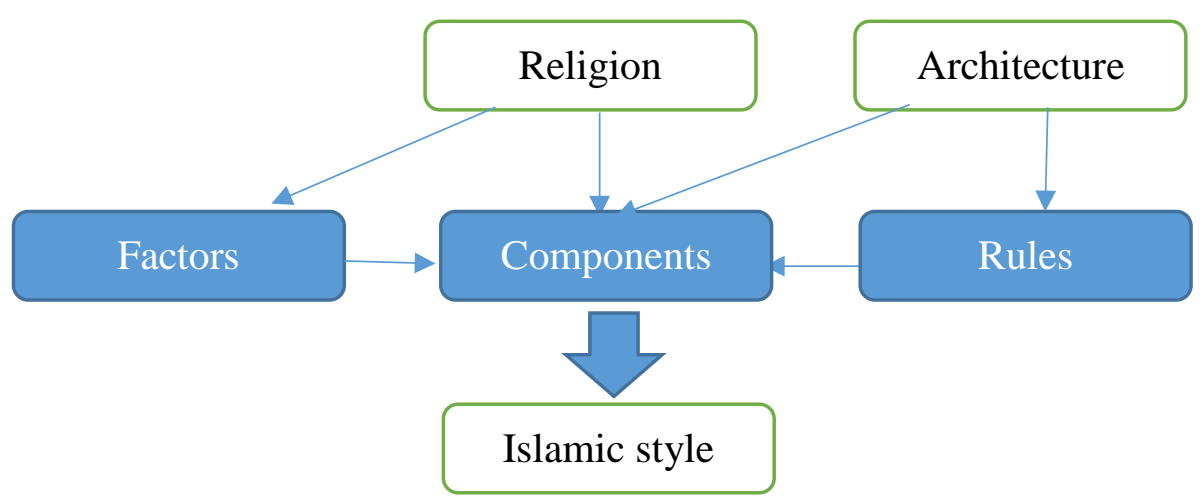

(Source: Researcher)

\section{Figure 3: The Framework of The Study}

\section{Methodology}

The study is a mix-mode methodology, which applied qualitative and quantitative approach to collect and analyse the data from two main source. The qualitative mode used the in-depth interview with experts selected by purposeful sampling technique, which are 4 academics researcher in the Islamic style. Qualitative method is the way to reach the aims any study in depth depending on quality of data not quantity (Ralph, Birks, \& Chapman, 2015). While, the quantitative mode used checklist to observe the visual analysis of the interior space of the selected buildings from various Islamic country. The selected building chosen under criteria depending on the heritage value and the importance of buildings. The analysis of the interview follows the content analysis, while the quantitative method used a static percentage.

The questions of the interview related to the quality of the interior space. However, the main question is "from your experiences what are the interior design elements in the Islamic building that reflect the quality of the space?". While the in-depth questions are, "to what extend do you think Islam as religion impact the interior design of the building that used by Muslims?" and "how can designers create spirit of the Islamic style in the interior space".

The checklist included three main sessions. The first session is related to the principles type and level of use. The session is related to the components of the interior space. While, the last session linked the first and second session by observing the relationships and factors influenced the interior space. The both collected data from interview and observation checklist are triangulated to show the results of the analysis and illuminate the finding, which is type of validation for the data in the mix methodology mode (Creswell, 2014).

\section{Findings and Discussion}

The elements of interior design in the current study referees to the architectural elements in the interior space. There are various type elements that included in the interior space of the heritage buildings that reflect that originality of the style. However, most of the experts highlighted the importance of the interior design elements in the Islamic style in the quality and originality of the style. The experts linked the quality to the originality in shape and function. However, one of the experts highlighted three main elements, which are, geometric patterns, arches, and ironwork. 
“ ...actually there are a lot in Islamic architecture, but for me, ornaments...the geometric type, the type of arches..i think also metal ornament everywhere in the Islamic building have a role in the quality" (Interview No. 2)

The Islam as religion impacted the interior element particularly and interior space in general as the experts mentioned. The impact come from the principle of Islam in general such as simplicity, human scale, and the important of function. The experts how is a researcher and lecturer in the Islamic architecture area answered the questions as following:

"Islam is the source of all architecture, art, and design...the designers in all areas of study reflects the values of the religion in the producing processes... by the way this not in Islam, but in all religions because the designers impacted from the cultural space..i can see simple elements few decorative and coloure, the building respect the users and the space and building designed for real needs. All these come from the religion values." (Interview No. 4)

The majority of experts explained that designers can reach the originality of the Islamic style by few steps. First step is to analyse and study the background about the function or the building that want to design. Step two; follow the principles that originally used in Islamic style. While, the last step is to include the cultural values and needs, because without including the needs of users, the place will be non-adapted from the users.

The observation from Islamic style interior design show that the quality of interior design depended $72 \%$ on the details level of the interior design element, which show the originality of the design. The main component of the Islamic style in the interior space are shown in table 1.

Table 1: The Essential Elements Of Interior Design In Islamic Style

\begin{tabular}{llll}
\hline Components & Place of use & Building type & Notes \\
\hline Stone ornaments & Walls & houses, Masjid & $\begin{array}{l}\text { Originally used in the interior } \\
\text { space, but nowadays used in } \\
\text { the facades }\end{array}$ \\
Arches & Gallery, openings & $\begin{array}{l}\text { houses, Masjid, } \\
\text { market, schools } \\
\text { There are various type of } \\
\text { arches used according to the } \\
\text { building location and country } \\
\text { There are many type of iron } \\
\text { work design }\end{array}$ \\
Geometric & $\begin{array}{l}\text { Handrail, windows house } \\
\text { and doors, and } \\
\text { furniture }\end{array}$ & $\begin{array}{l}\text { Walls, } \\
\text { furniture }\end{array}$ & $\begin{array}{l}\text { Simple and balance are the } \\
\text { main characteristics }\end{array}$ \\
\hline
\end{tabular}

The observation of the principle in the interior space identifies many principles and relationships. The researcher highlighted main three principles, which are: Symmetry, Repetition, and Unity. Moreover, scaling, rhythm, and contrast are realised in the visual observation. These principles are specially used in the interior design in Islamic buildings, which considered the generator of the traditional identity. The process of design interior space with an Islamic style included two lines. The first line is connected to the complete Islamic style, which contained most of the architectural elements with principles of design. However, this line in the contemporary area less interested by the designers, because of the costumers, cost, functional needs. The second line is to use the minimum architecture elements and 
principles that can reflect the Islamic style in the interior space. These two line reflect the quality of the Islamic style in the interior space if it used.

\section{Conclusion and Recommendations}

The current paper highlighted the main rules to create and conserve the Islamic style of interior design, which few studies deal with in-depth analysis of the shape. The finding of relation between culture, religion, and interior design are the main aim of the study. The influences of culture and religion is very clear in the Islamic style, which used the principles, elements, and factors to serve the characteristics of the style. The simplicity, privacy, and originality is the main point that designers should consider in the design and conserve the interior space. However, the variety of elements form, colour, and principles reflect the unity in the space, which is the identity of Islamic style. The excessive modification in the style reflect different principles, which are out of Islamic principles. Therefore, the study recommended to do deep analysis before starting to design Islamic style or in any restoration processes. Using different set of principles could lead to lose the typology of interior space in Islamic buildings.

\section{Acknowledgment}

The researcher would like to acknowledge the support of the Architectural engineering Department, University of Mosul during the research work.

\section{References}

Abdulrahman, A. A., \& Alimam, A. K. (2009). Interior design between subjective and objective. Al-academy Journal, 149-168.

Alabidin, M. Z. (2016). The Courtyard Houses of Syria. Retrieved January 8, 2019, from Muslims Heriatge: Discover the golden age of Muslim civilisation: http://muslimheritage.com/article/courtyard-houses-syria

Al-Jameel , A. H., \& Haj Kasim, H. (2012). Re- Implementation of Courtyard in Modern House Architecture in Iraq. International Conference on Theory of Architecture, ARCHTHEO 12 (pp. 1-15). Istanbul: Dokma.

Al-Darb Al-Ahmar District Mosques. (2017). Retrieved January 2, 2019, from World Monuments Fund: https://www.wmf.org/project/al-darb-al-ahmar-district-mosques

AMRO, D. K. (2014). An analysis of contemporary cortyard houses in Amman, Jordan.

Burckhardt, T. (2009). Art of Islam: Language and Meaning. London: World Wisdom, Inc,.

Caan, S. (2011). Rethinking Design and Interiors Human Beings in the Built Environment. London: Laurence King Publishing Ltd.

Creswell, J. W. (2014). Research Design Qualitative, Quantitative and Mixed methods approaches. Lincoln: Sage publications, Inc.

Fletcher, B. (2008). A History of Architecture on the Comparative Method for the Student, Craftsman \& Amateur. Princeton: B.T. Batsford, Limited.

FOROOZANI, M. (1991). Principles of aesthetics in islamic architecture. Pbriodica polytbchnica sbr, 35(3-4), 189-200.

Hedayat, A. (2012). Inquiry on Interrelationships Between Architecture and Fashion Design. Gazimağusa: Eastern Mediterranean University.

Hillenbrand, R. (1999). Islamic Art and Architecture. London: Thames \& Hudson World of Art series.

Jasim, H. S. (2015). Courtyard is basic pattern in tradition islamic architecture: as prototype. 12th International conference "Standardization, Protypes and quality A means of Balkan countries' colloboration, (pp. 001-012). TURKEY. 
Kamel , D. M., \& Elhalaby, M. M. (2011). The Islamic quantitative and qualitative proportion theories in the educational process. INTERIOR DESIGN EDUCATORS COUNCIL (pp. 42-44). Denver: IDEC.

Mahmoud, H. T. (2017). Interior Architectural Elements that Affect Human Psychology and Behavior. International Journal on: The Academic Research Community Publication, 1(1), 1-10.

Ralph, N., Birks, M., \& Chapman, Y. (2015). The Methodological Dynamism of Grounded Theory. International Journal of Qualitative Methods, 14(4), 1-6. doi:10.1177/1609406915611576

Thanoon, A. A. (2007). Popular architecture of old city of Mosul the architecture of the traditional house. International conference forasian and north african studies(ICANS 38) (pp. 1341-1356). Ankara: Middle Esat Technichal Uinversity.

Ujang, N. (2012). Place Attachment and Continuity of Urban Place Identity. Procedia - Social and Behavioral Sciences(49), 156 - 167.

Weinthal, L. (2013, June 11). Interior Skins. International Journal of Interior Architecture \& Spatial Design.

Zanten, W. V. (2002). Glossary intangible cultural heritage. international meeting of experts at UNESCO. 